\title{
West Nile Virus Outbreak in Houston and Harris County, Texas, USA, 2014
}

\section{Diana Martinez, Kristy O. Murray, Martin Reyna, Raouf R. Arafat, Roberto Gorena, Umair A. Shah, Mustapha Debboun}

Since 2002, West Nile virus (WNV) has been detected every year in Houston and the surrounding Harris County, Texas. In 2014, the largest WNV outbreak to date occurred, comprising 139 cases and causing 2 deaths. Additionally, 1,286 WNV-positive mosquito pools were confirmed, the most reported in a single mosquito season.

W est Nile virus (WNV) emerged in the United States in 1999 and in Texas in 2002 (1). During 2002-2011, Texas reported 2,202 WNV cases and 135 deaths (2). In 2012, the largest statewide WNV outbreak in Texas occurred; 1,868 cases and 89 deaths were reported (3).

Every year since 2002, WNV has been detected in Houston and the surrounding Harris County (Houston/Harris County), the third most populous US county. This area was affected by the statewide outbreak in 2012, and then in 2014, the largest WNV outbreak to date occurred in this area. We examined the epidemiology of WNV in Houston/ Harris County in 2014.

\section{The Study}

We investigated epidemiologic surveillance data on reported WNV case-patients who had onset of illness during January 1, 2002-December 31, 2014, from the Texas Department of State Health Services and the Houston-area local health departments: Harris County Public Health (HCPH) and the Houston Health Department (HHD). We determined case severity (West Nile neuroinvasive disease [WNND] and West Nile fever [WNF]) by using established criteria (4) and calculated attack rates by demographic characteristics by using population estimates for 2014 (5). We used Stata 14.0 (StataCorp LLP, College Station, TX, USA) to conduct statistical analyses.

During 2002-2014, a total of 650 human WNV cases were reported to HCPH and HHD (online Technical

Author affiliations: Harris County Public Health, Houston, Texas, USA (D. Martinez, M. Reyna, R. Gorena, U.A. Shah, M.

Debboun); Baylor College of Medicine and Texas Children's Hospital, Houston (K.O. Murray); Houston Health Department, Houston (R.R. Arafat)

DOI: https://doi.org/10.3201/eid2308.170384
Appendix Table 1, https://wwwnc.cdc.gov/EID/article/23/ 8/17-0384-Techapp1.pdf), including 35 deaths (case-fatality rate $5.4 \%$ ). This total represented $14 \%$ of all cases reported from Texas during this period. The epidemic curve revealed an increased number of cases in 2002, 2006, 2012, and 2014 (Figure 1), which correlated with the minimum infection rate for mosquitoes (Pearson correlation coefficient $r=0.74$ ).

During 2014, Harris County reported its highest number of WNV human cases to date: 139 cases and 2 deaths. This total represented $37 \%$ of all cases in Texas. Most $(76 \%)$ cases were WNND (Table 1). Overall, incidence was 3.26 cases $/ 100,000$ population; $69 \%$ of case-patients were male. Mean case-patient age was 57 years (range 6-92 years); most $(76 \%)$ case-patients were $\geq 45$ years of age. Attack rates increased with age, from 0.4 cases $/ 100,000$ population for those $<18$ years of age to 14.5 cases $/ 100,000$ population for those $\geq 65$ years of age. A higher attack rate was observed among non-Hispanic whites when compared with black, Hispanic white, and Asian populations. We did not detect statistically significant differences between WNND and WNF occurrence related to race/ethnicity, age, or sex (all $\mathrm{p}$ values $>0.05$ ). This finding is in contrast to the Texas 2012 statewide outbreak, during which being male, $>65$ years of age, and of a minority population were statistically associated with WNND (3). Although results from this study had similar trends, the lack of statistical significance was likely caused by the small sample size of WNF cases $(\mathrm{n}=34)$.

In 2014, the HCPH Mosquito and Vector Control Division also identified the largest number of WNV-positive mosquito pools to date: 1,286 positive pools were identified through the Rapid Analyte Measurement Platform (Response Biomedical Corp, Burnaby, British Columbia, Canada) (Table 2). In Harris County, 782,551 mosquitoes were collected, comprising 34 of 56 species recorded (6). We tested 12,608 mosquito pools from 19 species (online Technical Appendix Table 2) and confirmed in 1,285 Culex quinquefasciatus (Say) mosquito pools and in 1 Aedes albopictus (Skuse) pool. The first WNV-positive mosquito pool was detected during epidemiologic week 23 of 2014 (June 6). Viral detection continued for 20 weeks, ending in week 42 (October 14). The peak of positive pools $(n=168)$ occurred during week 30 (July 20-26). In comparison, dates of symptom onset for human cases occurred during February 5-December 1, 2014, and peaked during week 33 (Figure 1). 


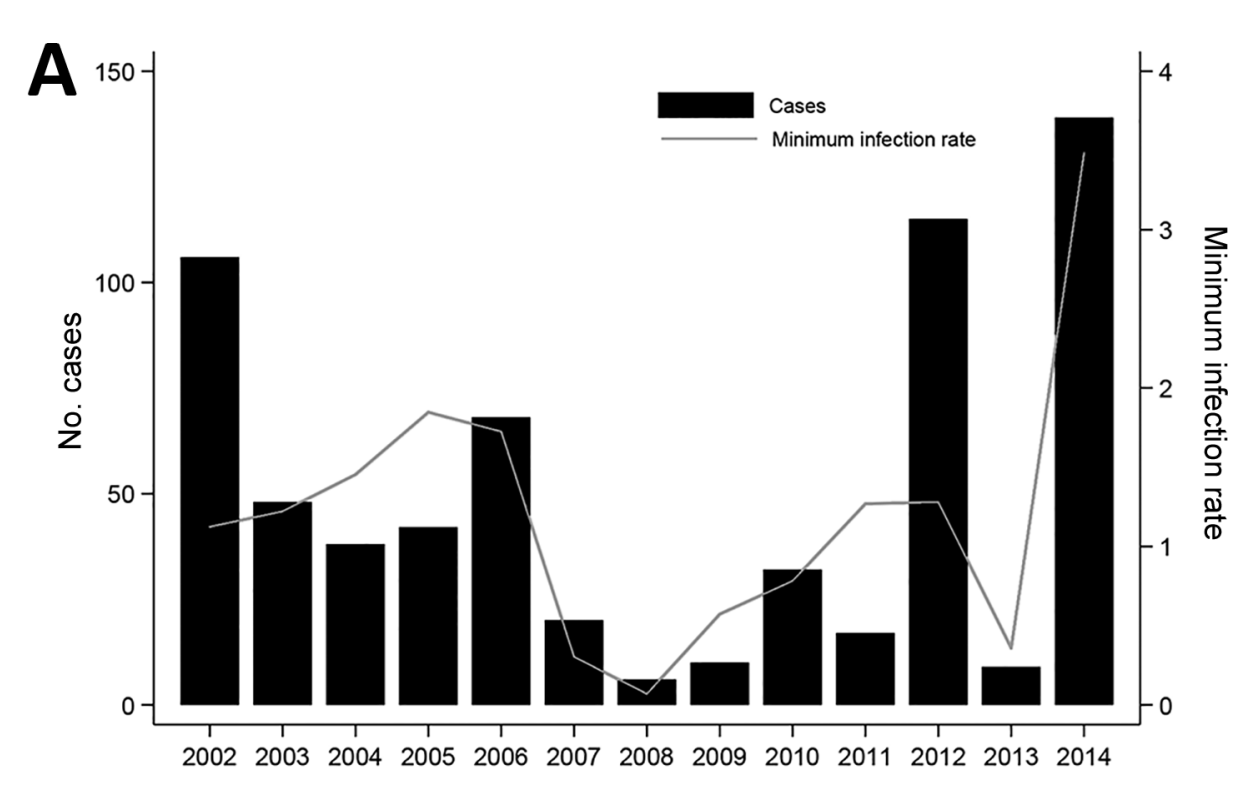

Figure 1. Epidemic curves depicting number of cases of West Nile among humans and minimum infection rate (MIR) of positive mosquito pools by year (A) and by epidemiologic week. (B), Houston/Harris County, Texas, 2002-2014 MIR was calculated by the formula (no. positive mosquito pools $\times 1,000) /$ no. female mosquitoes pooled).

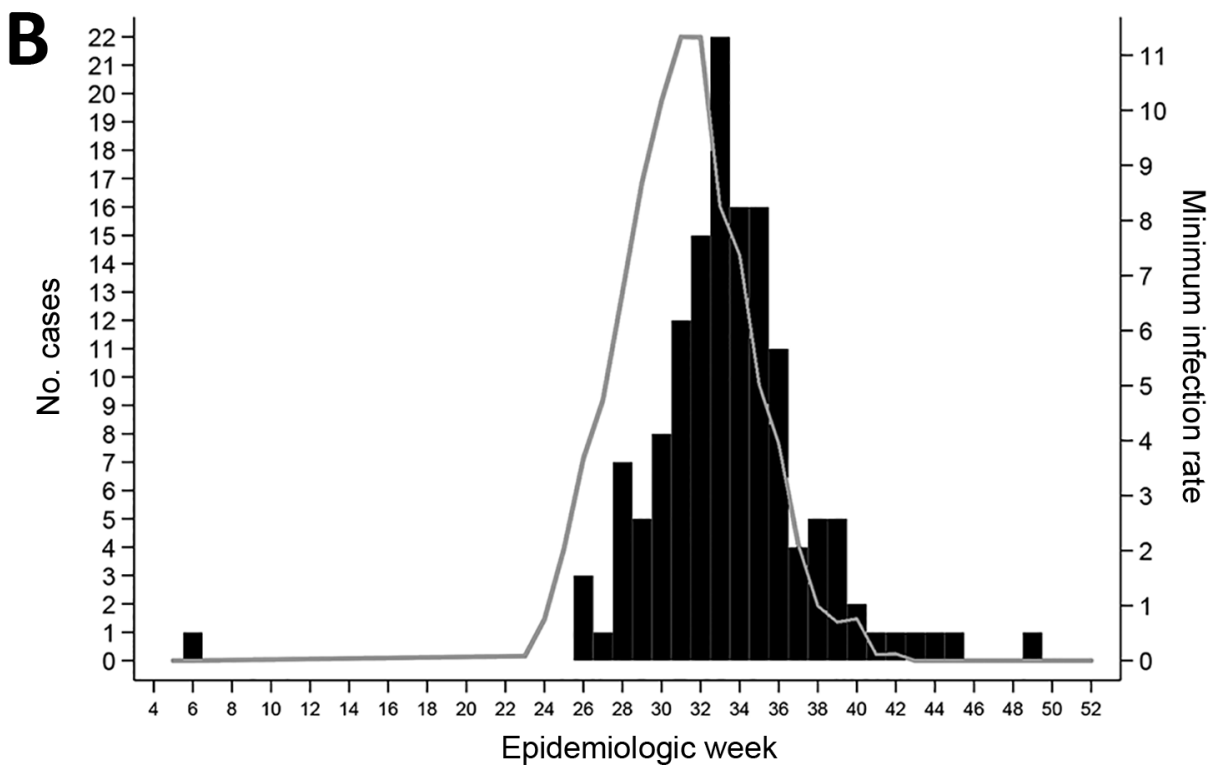

We used ArcMap 10.2.1 (Environmental Systems Research Institute, Inc. [ESRI], Redlands, CA, USA) to determine the distributions of positive mosquitoes and residences of case-patients where available $(\mathrm{n}=128)$. Throughout the transmission season, WNV was detected in 237 (88\%) of the 268 Mosquito Control Districts (MCD) in Harris County. We used the Optimized Hot Spot Analysis Tool (ArcGIS Pro; ESRI, Redlands, CA, USA) to calculate the Getis-Ord Gi statistic, which we used to determine statistically significant clusters (hotspots) of mosquito activity. We then converted data for case-patients to graduated frequency dots to determine spatial patterns. In the hotspot analysis (Figure 2), red shading indicates MCDs with statistically significant clustering of positive mosquito pools $(90 \%, 95 \%$, and $99 \%$ CIs) compared with neighboring MCDs. The dark blue areas show where mosquito-positive pools were statistically less likely to occur. We observed a similar hotspot pattern in prior years (D. Martinez et al., Harris County Public Health, Houston, TX, unpub. data). Hotspots are likely related to ecologic areas with higher vegetation and creeks (7).

The 2014 WNV outbreak in Houston/Harris County was unexpected, particularly because transmission activity across the state was at low levels, and only 379 cases were reported statewide. It is likely that the actual number of WNV cases was considerably higher, particularly considering that $76 \%$ of reported case-patients had severe WNND, 
Table 1. Demographics and attack rates of West Nile virus cases reported to HCPH and HHD, Houston/Harris County, Texas, USA, $2014^{*}$

\begin{tabular}{|c|c|c|c|c|}
\hline Case-patient characteristics & $\begin{array}{c}\text { All case-patients, no. (\%), } \\
n=139\end{array}$ & $\begin{array}{c}\text { Attack rate } \dagger / 100,000 \\
\text { population }\end{array}$ & $\begin{array}{c}\text { WNF, no. (\%), } \\
n=34\end{array}$ & $\begin{array}{c}\text { WNND, no. }(\%), \\
n=105\end{array}$ \\
\hline \multicolumn{5}{|l|}{ Sex } \\
\hline M & $96(69)$ & 4.5 & $26(76)$ & $70(67)$ \\
\hline $\mathrm{F}$ & $43(31)$ & 2.0 & $8(24)^{\prime}$ & $35(33)$ \\
\hline \multicolumn{5}{|l|}{ Age, y } \\
\hline$<18$ & $5(4)$ & 0.4 & $1(3)$ & $4(4)$ \\
\hline $18-24$ & $3(2)$ & 0.7 & $1(3)$ & $2(2)$ \\
\hline $25-44$ & $25(18)$ & 1.9 & $6(18)$ & $19(18)$ \\
\hline $45-64$ & $52(37)$ & 5.2 & $11(32)$ & $41(39)$ \\
\hline$\geq 65$ & $54(39)$ & 14.5 & $15(44)$ & 39 (37) \\
\hline \multicolumn{5}{|l|}{ Race/ethnicity } \\
\hline White, non-Hispanic & $73(53)$ & 5.3 & $17(50)$ & $56(53)$ \\
\hline Black & $19(14)$ & 2.4 & $6(18)$ & $13(12)$ \\
\hline White, Hispanic & 30 (22) & 1.7 & $4(12)$ & $26(25)$ \\
\hline Asian & $2(1)$ & 0.7 & $1(3)$ & $1(1)$ \\
\hline Other/unknown & $15(11)$ & NA & $6(18)$ & $9(9)$ \\
\hline \multicolumn{5}{|c|}{$\begin{array}{l}\text { *HCPH, Harris County Public Health; HHD, Houston Health Department; WNF, West Nile fever; WNND, West Nile neuroinvasive disease; NA, not } \\
\text { applicable. } \\
\text { †Attack rates based on } 2014 \text { population estimates from the Texas State Data Center (3), accessed February 10, 2017. Total population of Harris } \\
\text { County }=4,269,608 \text {. }\end{array}$} \\
\hline
\end{tabular}

which indicates a probable diagnostic bias. Prior studies showed that $<1 \%$ of WNV infections manifest as WNND $(8,9)$. A recent study in Houston showed that WNV testing was ordered for only $37 \%$ of viral meningitis/encephalitis case-patients (10), further highlighting concerns for underestimation of the true extent of disease.

We recently reported that WNV activity appears to have a 3-year pattern that showed increases in reported cases observed in 2003, 2006, 2009, and 2012 (2,3). During the years in which we observed increased numbers of cases, we also observed earlier detection of positive mosquito pools, which first appeared in May, compared to June in nonoutbreak years. Vector abundance and increased amplitude of transmission are likely driven by ecologic and environmental factors. In 2014, we were unsure why such a large outbreak occurred in this region compared with prior years. Weather patterns during 2012-2014 were different: 2012, after the drought of 2011, had mild winter temperatures. Conversely, 2014 had below-average winter temperatures, above-average rainfall, and no drought conditions. Further research would aid our understanding of factors that drive WNV transmission.

Vector surveillance is vital to disease prevention. The year-round Integrated Mosquito Management Program includes surveillance-guided vector control. It is difficult to estimate the number of WNV cases prevented; however, considering the high minimum infection rate in 2014 in the densely populated city of Houston, we believe that 139 cases are a much lower number than what could have otherwise occurred if no surveillance/control activities had been implemented. Barber et al. found that vector control is costeffective if at least 15 cases of WNND are prevented (11).

Continuous WNV disease activity has had a high economic effect on the Houston/Harris County area. By using estimates provided by Barber et al. (11) (adjusted to 2014 US dollar value [12]), we calculated the acute medical care and productivity costs of the 2014 outbreak to be $\approx \$ 6$ million (online Technical Appendix Table 3). In addition to high medical costs, costs related to rehabilitation/long-term care, surveillance, and vector control would be considerable.

\section{Conclusions}

The 2014 outbreak of WNV in the Houston/Harris County area is a reminder of the continuous effect and the unpredictable nature of disease transmission. With no specific therapeutic options or vaccine available, the costs related to medical care, surveillance, and vector control will continue to mount. Public health authorities should remain vigilant to prevent mosquitoborne infections. We expect endemic levels of transmission and occasional epizootics in the years to come.

\begin{tabular}{|c|c|c|c|c|c|c|c|}
\hline Trap type† & Species & No. traps & Total no. pools & Females pooled & WNV & SLE & WNV MIR \\
\hline CDC Gravid Trap & Culex quinquefasciatus & 3,971 & 5,025 & 192,441 & 716 & 0 & 3.72 \\
\hline CDC Miniature Light Trap & Cx. quinquefasciatus & 3,748 & 4,617 & 154,124 & 566 & 1 & 3.67 \\
\hline Biogents Sentinel Trap & Cx. quinquefasciatus & 926 & 54 & 680 & 3 & 0 & 4.41 \\
\hline CDC Gravid Trap & Aedes albopictus & 1,315 & 359 & 952 & 1 & 0 & 1.05 \\
\hline
\end{tabular}

*WNV, West Nile virus; SLE, St. Louis encephalitis virus; MIR, minimum infection rate.

†CDC Gravid Trap and CDC Miniature Light Trap, John W. Hock Company, Gainesville, FL; Biogents Sentinel Trap, Biogents AG, Regensburg, Germany. 


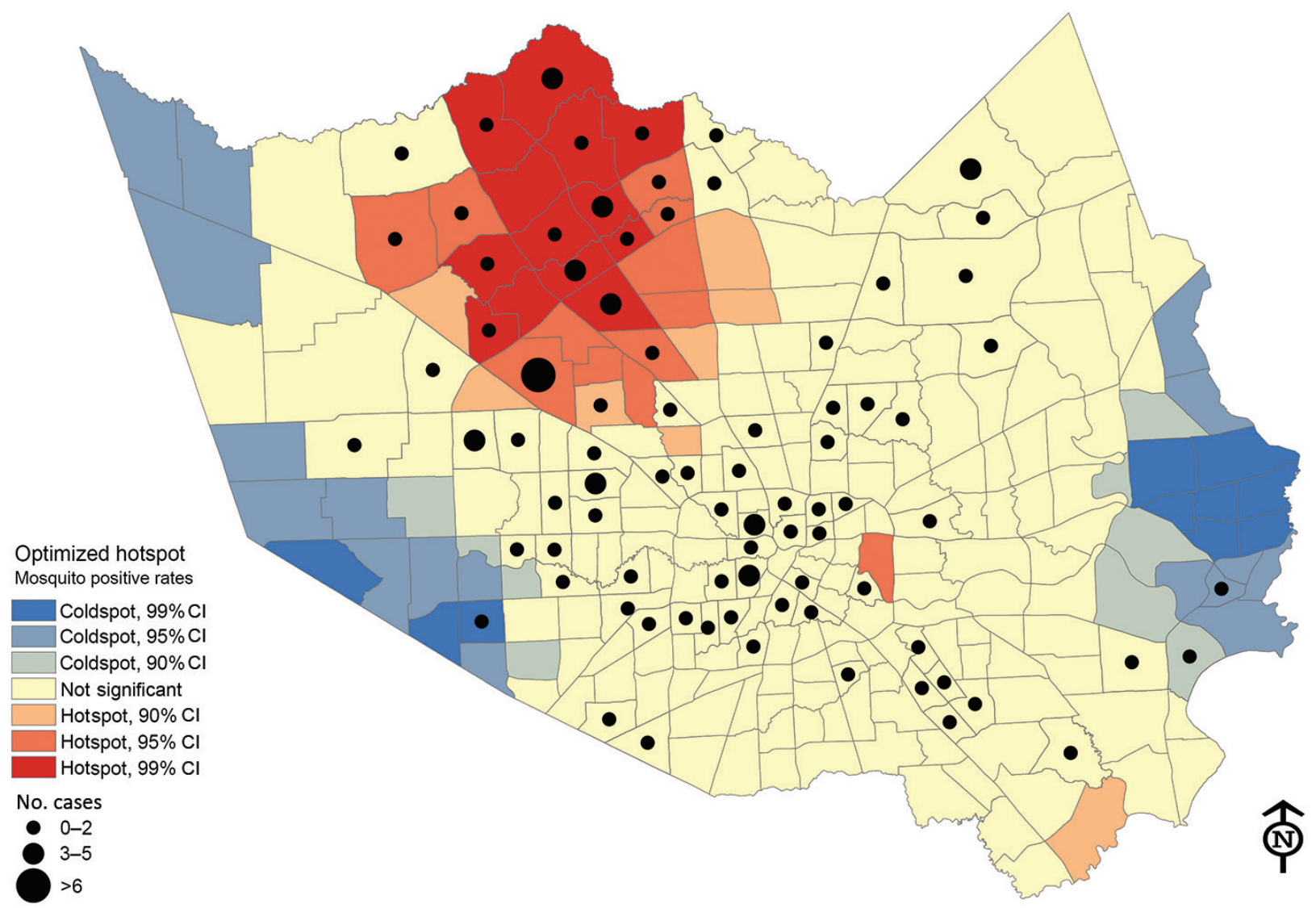

Figure 2. Optimized hotspot analysis results showing residential locations of persons who had West Nile virus and their association with positive mosquito hotspots, Houston/Harris County, Texas, 2002-2014. Red "hot" areas represent statistically significant high-risk viruspositive mosquito activity, compared with blue "cold" areas with low risk for positive mosquitoes.

\section{Acknowledgments}

The authors thank all epidemiologists at both health departments and mosquito surveillance technicians at Harris County Public Health Mosquito and Vector Control Division for their assistance with data collection. We also thank Melina Evdemon and Chris Fredregill for their technical assistance during the creation of the figures.

This project was generously funded in part by the National Institutes of Health, National Institute of Allergy and Infectious Diseases (5R01AI091816-01).

Dr. Martinez is the Epidemiology Program Manager/Senior Epidemiologist for Harris County Public Health and serves as liaison for programmatic, quality assurance, and surveillance activities of the Epidemiology Program. Her research interests are emerging and acute infectious disease epidemiology and surveillance.

\section{References}

1. Lillibridge KM, Parsons R, Randle Y, Travassos da Rosa AP, Guzman H, Siirin M, et al. The 2002 introduction of West Nile virus into Harris County, Texas, an area historically endemic for St. Louis encephalitis. Am J Trop Med Hyg. 2004;70:676-81.

2. Nolan MS, Schuermann J, Murray KO. West Nile virus infection among humans, Texas, USA, 2002-2011. Emerg Infect Dis. 2013;19:137-9. http://dx.doi.org/10.3201/eid1901.121135

3. Murray KO, Ruktanonchai D, Hesalroad D, Fonken E, Nolan M. West Nile virus, Texas, USA, 2012. Emerg Infect Dis. 2013;19:1836-8. http://dx.doi.org/10.3201/eid1911.130768

4. Centers for Disease Control and Prevention. Arboviral diseases, neuroinvasive and non-neuroinvasive 2014 case definition [cited 2017 Apr 11]. https://wwwn.cdc.gov/nndss/conditions/arboviraldiseases-neuroinvasive-and-non-neuroinvasive/case-definition/2014/

5. The Texas State Data Center TTSD. Texas population projections program [cited 2017 Apr 11]. http://txsdc.utsa.edu/Data/TPEPP/ Projections/Index.aspx

6. Nava MR, Debboun M. A taxonomic checklist of the mosquitoes of Harris County, Texas. J Vector Ecol. 2016;41:190-4. http://dx.doi.org/10.1111/jvec.12212

7. Nolan MS, Zangeneh A, Khuwaja SA, Martinez D, Rossmann S, Cardenas V, Murray KO. Proximity of residence to bodies of water and risk for West Nile virus infection: a case-control study in Houston, Texas. J Biomed Biotechnol. 2012;159578. http://dx.doi.org/10.1155/2012/159578

8. Mostashari F, Bunning ML, Kitsutani PT, Singer DA, Nash D, Cooper MJ, et al. Epidemic West Nile encephalitis, New York, 1999: results of a household-based seroepidemiological survey. 
Lancet. 2001;358:261-4. http://dx.doi.org/10.1016/ S0140-6736(01)05480-0

9. Carson PJ, Borchardt SM, Custer B, Prince HE, Dunn-Williams J, Winkelman V, et al. Neuroinvasive disease and West Nile virus infection, North Dakota, USA, 1999-2008. Emerg Infect Dis. 2012;18:684-6. http://dx.doi.org/10.3201/ eid1804.111313

10. Vanichanan J, Salazar L, Wootton SH, Aguilera E, Garcia MN, Murray KO, et al. Use of testing for West Nile virus and other arboviruses. Emerg Infect Dis. 2016;22:1587-93. http://dx.doi.org/ 10.3201/eid2209.152050
11. Barber LM, Schleier JJ III, Peterson RK. Economic cost analysis of West Nile virus outbreak, Sacramento County, California, USA, 2005. Emerg Infect Dis. 2010;16:480-6. http://dx.doi.org/10.3201/ eid1603.090667

12. Bureau of Labor Statistics Consumer Price Index Calculator [cited 2017 Feb 13]. http://www.bls.gov/data/inflation calculator.htm

Address for correspondence: Kristy O. Murray, Baylor College of Medicine, National School of Tropical Medicine, 1102 Bates Ave, Ste 550, Houston, TX 77030, USA; email: kmurray@bcm.edu

\section{March 2010: Vectorborne Infections}

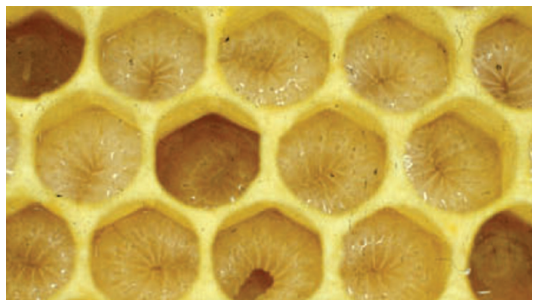

- Preparing a Community Hospital to Manage Work-related Exposures to Infectious Agents

- Bartonella spp. Transmission and Ticks

- Potential for Tick-borne Bartonelloses

- Malaria in Areas of Low Endemicity, Somalia, 2008

- West Nile Virus in American White Pelicans, Montana

- Murine Typhus in Austin, Texas

- Chikungunya Virus Infection during Pregnancy, Réunion, France

- Mumps Outbreak in Hospital, Chicago, Illinois

- Reservoir Hosts for Amblyomma americanum Ticks

- Borrelia, Ehrlichia, and Rickettsia spp. in Ticks, Texas

- Legionella pneumophila Serogroup 1 Clones, Ontario, Canada

- Invasive Haemophilus influenzae Disease, Europe, 1996-2006

- Vaccine Preventability of Meningococcal Clone, Germany

- Avian Bornavirus and Proventricular Dilatation Disease
- Climate Warming and Tick-borne Encephalitis, Slovakia

- Cost Analysis of West Nile Virus Outbreak, Sacramento County, California

- Paenibacillus larvae Bacteremia in Injection Drug Users

- Rickettsia helvetica in Patient with Meningitis, Sweden

- Influenza A (H3N2) Variants with Reduced Sensitivity to Antiviral Drugs

- Sarcocystis Species Lethal for Domestic Pigeons, Germany

- Candidatus Bartonella mayotimonensis and Endocarditis

- First-wave Pandemic (H1N1) 2009, Northern California

- Experimental Infection of Squirrel Monkeys with Nipah Virus

- Q Fever in Greenland

- Bluetongue Virus Serotypes 1 and 4 in Red Deer, Spain

- Spotted Fever Group Rickettsiosis, Brazil

- Kissing Bugs and T. cruzi, Arizona

- Banna Virus, China, 1987-2007

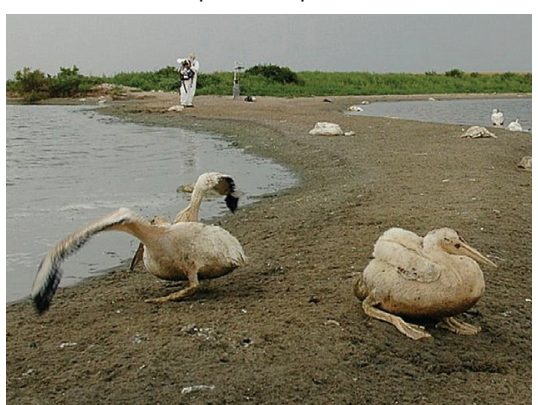

- Parvovirus 4-like Virus in Blood Products

- Terrestrial Rabies and Human Postexposure Prophylaxis, New York

- Skin

Infections and Staphylococcus aureus Complications in Children, England

- Pandemic (H1N1) 2009 Virus Infection in Domestic Cat

- School Closure and Mitigation of Pandemic (H1N1) 2009, Hong Kong

- Global Origin of Mycobacterium tuberculosis in the Midlands, UK

- Quinine-Resistant Malaria in Traveler Returning from Senegal

- Putative New Lineage of West Nile Virus, Spain

- Venezuelan Equine Encephalitis and 2 Human Deaths, Peru

- Extensively Drug-Resistant Mycobacterium tuberculosis from Aspirates, South Africa

- Rhabdomyolysis and Pandemic (H1N1) 2009 Pneumonia in Adult

- Yersinia pseudotuberculosis and Y. enterocolitica Infections

- Measles Outbreak, the Netherlands, 2008

- Neurologic Manifestations of Pandemic (H1N1) 2009 Virus Infection 